\title{
Introduction to Sociocybernetics (Part 1): Third Order Cybernetics and a Basic Framework for Society
}

\author{
Roberto Gustavo Mancilla \\ LLB. Instituto Tecnológico y de Estudios Superiores de Monterrey, \\ LLM University of California, Berkeley \\ robi357@hotmail.com
}

Table of Content:

Introduction

1 Cybernetics

a) First and second order cybernetics: Observed and observing systems

b) Third order

i) The transition from second to third order cybernetics: social autopoiesis

ii) Points of convergence between second and third order cybernetics

iii) Mutually observing systems

2 Society: An outline of a cybernetic model

a) Micro perspective: The creation of social reality

i) Intentionality

ii) Assignation of function and status functions

iii) Institutional facts

iv) Deontic powers

b) Meso perspective: Social Systems

i) Social reality

ii) Defining features of social systems

3 Macro perspective: Society as a complex adaptive system

a) Society as a complex system

b) Definition of society

Conclusion 


\section{Introduction}

Like Luhmann created a humanless theory society, these papers will attempt to create a basic framework for cybernetic analysis of social systems that prescinds of him, that is, there will not be an application of terminology of second cybernetics-autopoiesis- to social systems. The purpose of this first paper in the series is to initiate the efforts towards an idea of a third order in cybernetics.

Second order cybernetics will be used as a biological basis for social processes. It will be stated that where first cybernetics deals with observed systems and second with observing systems, the third order studies mutually observing systems, which endows them features of the first two types.

Also, while first cybernetics deals with allopoietic machines, and second with autopoietic or living machines, the object of analysis of third cybernetics is language as a cognitive machine that creates a common domain of interaction between living systems in order to interact. These types of machines are abstract mechanisms that have a basis in the human brain and that store, retrieve, process and create information, and as such is both allopoietic and autopoietic; therefore, cognitive machines are omnipoietic.

This paper will also account for the creation of social reality by means of a collective assignation of functions by means of speech acts and will use the philosophical scholarship of John Searle to achieve this purpose. ${ }^{1}$ Also, society will be analyzed under the lens of complex systems theory. Searle's idea of social ontology explains Society on a micro level; the meso level is studied by social systems and complex systems theory enables the study of society from a macro perspective.

\section{Cybernetics}

Cybernetics is an interdisciplinary approach to organization, irrespective of a system's material realization. ${ }^{2}$ The contents of this discipline can be divided by its history and content in two: first order cybernetics, which encompasses machines and second order cybernetics, which centers on living systems. ${ }^{3}$ Although the usage of biological cybernetics on social systems is widespread, the idea of a third order in cybernetics as the domain of social systems has been talked about by some scholars.

\footnotetext{
${ }^{1}$ Searle, J.R. (1998). Mind, Language and Society. Basic Books, 8.

${ }^{2}$ Cybernetics. In Web Dictionary of Cybernetics and Systems. Retrieved from http://pespmc1.vub.ac.be/ASC/CYBERNETICS.html

${ }^{3}$ Geyer, F., van der Zouwen, J. (Eds.) (2001), Introduction. In Sociocybernetics: Complexity, Autopoiesis and Observations of Social Systems. Westport, Connecticut: Greenwood Press, 1.
} 


\section{a) First and second order cybernetics: Observed and observing systems}

Maturana and Varela (2012) distinguish allopoietic machines from autopoietic machines (living systems). The former is defined as "machines that have as a product of their function something different from themselves" The machines that cannot product their own components are used for a purpose, they are controlled systems, while those that can are observing system and can control other systems. The authors coincide with this direction when they say: "Man made machines are all made with some purpose... This aim usually appears expressed in the product of the operation of the machine, but not necessarily so".

Because the purpose of the machines is set by their creators and users, it can be said that first order cybernetics is teleological. It can be concluded then that first order cybernetics is the study of organization (observation and teleology) in allopoietic machines.

Maturana and Varela (2012) define autonomy as the: "Self asserting capacity of living systems to maintain their identity through the active compensation of deformation". This idea leads to the concept of autopoiesis. An autopoietic system is a machine that produces its own components and occupies a space in which it carries out its processes. It is important to note then that these types of machine are not teleological, that is, their purposes are not set by an observer. Living systems are teleonomical, that is, they have an apparent purpose or project of organization, which can be attributed to a causal feedback relation attributable to natural selection. ${ }^{5}$

Second order cybernetics is the study of the organization in autopoietic machines, which are able to build their own components, and possess cognizance which allows them to observe and control other machines.

Although both deal with machines, there are a set of differences between first and second order cybernetics. This can be summarized in the following schema:

\footnotetext{
${ }^{4}$ Maturana, H.R., Varela, F.J. (2012) Autopoiesis and Cognition: The Realization of the Living. Dodrecht: D. Reidel Publishing Company, 135.

${ }^{5}$ Lesne, A., Bourgine, P. (Eds.) (2006) Introduction. In Morphogenesis. Origins of Patterns and Shapes. Dodrecht: Springer, 11.
} 


\begin{tabular}{|l|l|}
\hline First order & Second order \\
\hline Heteropoietic & Autopoietic \\
\hline Inert systems & Living systems \\
\hline Teleological & Teleonomical \\
\hline Observed systems & Observing systems \\
\hline
\end{tabular}

First order machines are heteropoietic because they produce something different from themselves, by means of human design. This is a feature of inert systems, which are not able to build their own components, and which purposes are determined by an observer (teleology), therefore they are observed systems.

Second order machines produce only themselves, therefore they are living and their purpose is determined by the feedback with their environment (teleonomy). Some of them can be cognizant and capable of self description, which means that they observe and can use first order machines.

\section{b). Third order}

\section{i). The transition from second to third order cybernetics: social autopoiesis}

The application of second order cybernetics to social systems to explain their functioning has become commonplace in the students of cybernetics, sociology and complexity. In particular, the concept of autipoiesis, envisioned by Maturana and Varela has been stated as a feature of social systems.

To Fuchs the term autopoiesis is inappropriate for describing the self-organization of society, because it is a biological term that should not be directly mapped into social systems. Biological processes are the foundation of social systems, but not the core of sociability. He also says that one of the main problems of using these terms on social systems is that one cannot consider the individuals as their components. This results in subject-less theories of society that can't explain how individuals reproduce social structures and how the sociality is reproduced by them. ${ }^{6}$

\footnotetext{
${ }^{6}$ Fuchs, C. Concepts of Social Self-Organization. Retrieved from http://www.self-organization.org/results/papers/pdf/hsicpaper4.pdf
} 
Maturana and Varela (2012) say that despite the fact that both organisms and societies are types of metasystems, the difference between them is the degree of autonomy in their components. While the units of an organism have little or no independence, those of social systems have a maximum degree of autonomy:

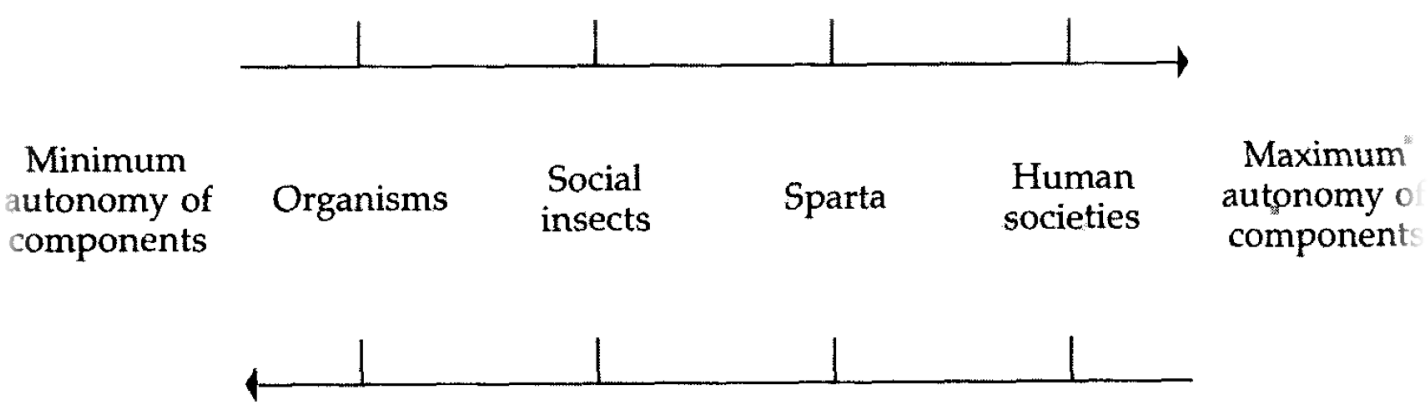

In summary, applying a second order cybernetics framework to social systems implies a distortion in the former and does not capture the full complexity of the latter. ${ }^{7}$

\section{ii). Points of convergence between second and third order cybernetics}

The subject of cognition is the bridges that unites autopoietic systems and social systems, because the former are systems capable of it, while the latter are the product of socialization, which is consequence of cognition. Maturana (2012) defines it in the following way:

A cognitive system is a system whose organization defines a domain of interactions in which it can act with relevance to the maintenance of itself, and the process of cognition is the actual (inductive) acting or behaving in the domain. Living systems are cognitive systems, and living as a process is a process of cognition. This statement is valid for all organisms, with and without a nervous system.

\footnotetext{
${ }^{7}$ Umpleby, S.A. What comes after second order cybernetics? Retrieved from http://www.gwu.edu/ umpleby/recent papers/2001 what comes after second order cybernetics.htm
} 
In its most basic sense cognition is the processing of information made by an autopoietic system in its interaction with what surrounds it (environment and other beings) with the purpose of sustaining itself. This will be called lower cognition.

Maturana (2012) distinguishes a set of degrees when it comes to the interactions that a system can have, he states three, each of which is contained in the preceding one:

- Cognitive domain: Comprises all the interactions of the organism and can be enlarged by adding new modes of interaction.

- Domain of interactions: Set of interactions into which an entity can enter.

- Domain of relations: Set interactions through the observer in which an entity can be observed.

Another interesting point brought forth by this author is his famous phrase: "Anything said is said by an observer", that is, to understand cognition the observer must comprehend his role in it. When one observes and interacts with the environment, one creates notions like that of entity (organisms for purposes of this study), when one distinguishes it from its surroundings and other similar things.

By observing and interacting, an entity can make representations of his surroundings and thus understand it and interact further with it, creating further constructs that constitute the cognitive domain in a recursive cycle that ends when the being loses is autopoiesis and dies.

One becomes an observer by "recursively generating representations of our interactions, and by interacting with several representations simultaneously we generate relations with the representations of which we can then interact and repeat this process recursively". An observer can define himself as an entity by identifying his own domain of interactions and yet remain as an observer if he treats them as independent entities. An entity can achieve self-observation by means of repeated self-description and selfconsciousness by means of self-observation (Maturana and Varela, 2012).

Self consciousness is the point of transition between lower cognition (which pertains second cybernetics) and that which belongs to human beings(which is the object of study of what will be called fourth order cybernetics), which will be called higher cognition. This is because when a system becomes fully self-conscious and observes itself, it can set its own purpose, which is tempered by the interaction with the environment. A self-observing system- unlike other cognitive systems- is both teleonomical and teleological.

Self-consciousness is a consensual phenomenon (not a biologic one) which comes from an independent domain of interactions from self-orienting behavior and lies entirely in the linguistic domain and requires a minimum of two interacting organisms with similar domains of interactions. It is both an interaction and a communication because these 
interrelated behaviors bring forth a cooperative system of consensual interactions in which the emerging conduct of the two organisms is relevant for both.

Language creates a cooperative domain of interactions between speakers through the development of a common frame of reference, although each speaker acts exclusively within his cognitive domain (Maturana and Varela, 2012).

Finally, to conclude the topic of cognition and to unite it with social systems it is useful to provide a notion of higher cognition and one of man. The first can be defined as: The processing (storage, retrieval, transformation, creation and transmission) ${ }^{8}$ of information made by an autopoietic system in its interaction with what surrounds it (environment and other beings) with the possibility of stating a purpose beyond self-sustainment.

Man is a deterministic and relativistic self-referring autopoietic system whose life acquires its peculiar dimension through self-consciousness. He constructs his rational systems based on arbitrarily accepted truths (premises), which he changes continually (Maturana and Varela, 2012).

\section{iii). Mutually observing systems}

Von Foerster takes Maturana's idea of "Anything said is said by an observer" and complements it by saying: "Anything said is said to an observer", and connects them in the following way: ${ }^{9}$

- An observer is characterized by being able to make descriptions.

- Observers connect through language.

- Society is formed by a common usage of language.

- The interrelation of these concepts is circular: it cannot be determined which one was first.

Taking this into consideration it can be said that third order cybernetics studies mutually observing systems. This point was reached before by Jon-Arild Johannssen and Arnulf Hauan (1994), who define third order cybernetics as "the relationship between observers". They deal with communication systems by centering on their communicative process, which is what holds them together. ${ }^{10}$ To them communication

\footnotetext{
${ }^{8}$ Stillings, N.A., Weisler, S.E., Chase, C., Feinstein, M.H., Garfield, J.L. Rissland, E.L. (1995), Cognitive Science: An introduction. (2nd ed.) Cambridge: MIT Press, 1.

${ }^{9}$ von Foerster, H., Cybernetics of Cybernetics. Retrieved from http://jlombardi.net/pdf/cyber_cyber.pdf

${ }^{10}$ Johannssen, J., Hauan, A. (1994) Communication- A Systems Theoretical Point of View (Third Order Cybernetics), Systems Practice, 7(1), 68.
} 
is "to take part in and share, that is, together to look after what is. From this understanding of communication, one might say that the knowledge is in the relationships between people who communicate, and not a property of the individuals involved".

Social systems have features of both first and second order cybernetics, which explains why it has been studied from both perspectives, although without a complete understanding of its nature. A third order cybernetic system has the following features:

- They are heteropoietic because they are created by means of the cognitive processes of a living system.

- They are both teleological and teleonomical systems because they can be used by an observing system for a purpose, but their purpose can also be determined as an adaptive reaction to an environment.

- The relationship between teleology and teleonomy is circular: the goals of the individual can be influenced by the environment, but also the former can influence the latter to achieve his goals.

- Because they are the product of the communication between them and their respective cognitive processes; social systems tend to imitate living systems.

Johannssen and Hauan(1994) state their framework for communication:

- People interact

- The interactions are messages, which contain three parts:

- An information part, where there is both explicit and implicit information

- A leading/ directing (or command) part, which means the intentional and influentional part.

- A relationship part. The message in a communicative process is always carried out in a loop. Messages run in circles, and return to their own source and control it; they are circular or recursive.

- The interactions operate in circular causal loops

- The smallest entity in communication is the triad action-reaction-resultant. The latter constitutes an understanding of the code.

- The information impact upon one element in the communication process is looked upon as interpretation and transformation of the information part in the message.

Although this framework was conceived for organizations, it results useful to incorporate it into social systems in general. Although they foresee the communicative aspect of third order cybernetics, which is the relationship between observing systems, they fail to state the nature of language (and its importance) in this relationship. 
In the same fashion that first and second order systems are machines of varying nature, so are third order systems, which are cognitive machines that help to create a common frame of reference between existing domains of interactions pertaining to different autopoietic systems. This can be inferred by the definition of language as "an abstract cognitive system that uniquely allows humans to produce and comprehend meaningful utterances". "Language is a third order cybernetic machine and it stands between Johannssen and Hauan's "people interact" and "the interactions are messages".

Although it will be seen in full detail in the paper relative to fourth order cybernetics, a tentative definition of cognitive machines can be this: Information processing mechanisms of the high order that has their basis within the neural network of human beings, that is, it is the cybernetics of human beings. High cognition as information processing can consist of storage, retrieval, transformation and creation of information, among other functions. Cognitive machines, to be considered as such, must do three functions:

- Storage and retrieval of information.

- Help to understand received information.

- Create new information.

Information is both their input and output, and it can be used either to create new data, different from that received or to broaden the existing information storage in the brain, which can result in the expansion of the cognitive domain. This wrecks havoc in the existing classification between allopoietic and autopoietic machines, because cognitive machines both create things other than themselves, but also can create or recreate themselves by means of their inputs. Cognitive machines are omnipoietic because they can produce both their own components and information other than itself. Omnipoiesis, that is, the ability to create all kinds of output (internal and external to self) is the distinguishing features of cognitive machines, which are the subject of study of third and fourth order cybernetic systems.

Also of importance are speech acts, which Ohio State (2011) defines as "actions that are performed only through using language: a term that describes the use of speech emphasizing the speaker's intention or goal in producing an utterance". An important distinction to be made is that language resides within the nervous system of autopoietic systems and it manifests itself outside of it by means of speech acts.

Maturana and Varela (2012) define the relations that define a machine as a unity and define the dynamics of interaction and subsequent transformations are called

\footnotetext{
${ }^{11}$ Ohio State University (2011) Language Files: Materials for an introduction to language and linguistics.(11th ed.) Columbus: Ohio State University, 695.
} 
organization, while a structure is the relations between components that integrate a concrete machine in a given space.

In the case of third order cybernetic machines, organization is comprised by language and structure by speech acts, and the material space where they manifest is in the biological cognitive processes of self-conscious autopoietic systems.

Language and speech acts are necessary for the creation of institutional facts, which are an assignation of function to objects and people by means of a collective intentionality expressed by means of a speech act. Institutional facts are cognitive machines that are structured in the cognitive processes of humans, who relate them to the object or person to whom they are assigning a value.

Money is the perfect example of such thing. The organization of the institutional fact is within the individuals knowledge of language, in words like "money", "dinero" and "argent". While the structure is materialized in the speech act by which "X counts as money in the context of social relations" 12 in the mind of the subjects of communication.

It was then said that language is a cognitive machine that bridges the gap between cognitive systems through speech acts and has a physical manifestation in the human brain. It also has the following features, as defined by Ohio State (2011):

- Modality: Means trough which messages can be conveyed and received, examples of this are writing, speaking and gestures.

- Semanticity: All signals in a communication system have a meaning or function.

- Pragmatic function: Languages must serve a useful purpose.

- Interchangeability: It is the ability of individuals to send and receive information.

- Cultural transmission: Certain aspects of a language can only be acquired trough interaction with other users of the system.

- Arbitrariness: The meaning of a language cannot be predicted by the form, nor the form is determined by the meaning.

- Displacement: It is the ability of a language to communicate about things and actions that are not preset in space or time while speakers are communicating.

- Productivity: It is the capacity of a language to convey novel messages by means of recombining existing units.

12 The formula is used by philosopher John Searle and is stated as " $\mathrm{X}$ counts as $\mathrm{Y}$ in $\mathrm{C}$ ". 
A speech act is observable behavior that can have a variety of aims, it is the materialization of language and as such is not restricted to the spoken word, it can also be a sign, a gesture or a set of words. ${ }^{13}$ Speech acts can be analyzed on three levels: ${ }^{14}$

- Locutionary, or direct speech act: It is an utterance that performs its function in a direct and literal manner.

- Perlocutionary, or indirect speech act: Utterance that performs its function in an indirect and nonliteral manner.

- Ilocutionary or perfomative speech act: A speech act that employs a performative verb, that is, a verb that denotes a linguistic action.

Speech acts have a direction of fit, which is the relation that exists between the propositional content of the utterance and an existing reality. There are four different types: ${ }^{15}$

- Word to world: The propositional content of the utterance fits an existing reality.

- World to word: The reality must change according to the content of the utterance.

- No propositional content, or "null": There is no difference between the utterance and the existing state of affairs.

- Double direction of fit: When the illocutionary act is satisfied, the world is transformed by the present action of the speaker to fit the propositional content by the fact that the speaker represents it as being so transformed.

Searle enumerates five types of illocutionary speech acts: ${ }^{16}$

- Assertives: They represent how things are (word to world direction of fit).

- Directives: They try to conduct human behavior to a purpose(world to word).

- Comissives: They are promises that commit the speaker to an action (world to word).

- Expressives: Exteriorizes the feelings and attitudes of the speaker (no direction of fit).

\footnotetext{
${ }^{13}$ Speech Acts. Stanford Encyclopedia of Philosophy. Retrieved from http://plato.stanford.edu/entries/speech-acts/

${ }^{14}$ Speech Acts. Stanford Encyclopedia of Philosophy. Retrieved from http://plato.stanford.edu/entries/speech-acts/Ohio State University (2011) Language Files: Materials for an introduction to language and linguistics.(11th ed.) Columbus: Ohio State University, 695.

${ }^{15}$ Speech Acts. Stanford Encyclopedia of Philosophy. Retrieved from http://plato.stanford.edu/entries/speech-acts/Vanderveken, D. Meaning and Speech Acts, (Vol. I). Retrieved from http://www.uqtr.ca/ vandervk/elementary_illocutionary_acts.pdf

${ }^{16}$ Searle, J.R. (2010) Making the Social World. New York: Oxford University Press, 69.
} 
- Declaration: There is a declaration which is to be materialized (double direction of fit).

Finally, the illocutionary force of a speech act is defined by Vanderveken in terms of seven features:

- Illocutionary point: This is the characteristic aim of each type of speech act.

- Degree of strength of the illocutionary point: Two illocutions can have the same point but differ along the dimension of strength.

- Mode of achievement: This is the special way, if any, in which the illocutionary point of a speech act must be achieved.

- Propositional content conditions: Some illocutions can only be achieved with an appropriate propositional content.

- Preparatory conditions: These are all other conditions that must be met for the speech act not to misfire.

- Sincerity conditions: Many speech acts involve the expression of a psychological state.

- Degree of strength of the sincerity conditions: Two speech acts might be the same along other dimensions, but express psychological states that differ from one another in the dimension of strength.

\section{Society: An outline of a cybernetic model}

\section{a) Micro perspective: The creation of social reality}

\section{i). Intentionality}

Now that the basic tenets of social cybernetics have been seen, it is important to see other concepts necessary to create a basic cybernetic perspective of Society. Searle (1983) gives an initial account of intentionality: “...is that property of many mental states and events by which they are directed or about or of objects and states of affairs in the world". 17 He also states that "some, not all, mental states and events have Intentionality. Beliefs, fears, hopes, and desires are Intentional; but there are forms of nervousness, elation, and undirected anxiety that are not Intentional".

Searle (1983) creates a theory of intentionality based on language, specifically, on speech acts. In this model, the intentional states have a representative content in a psychological mode (beliefs, hopes, fears or others) and while many of those contents

\footnotetext{
${ }^{17}$ Searle, J.R., (1983) Intentionality: An essay in the philosophy of the mind. Cambridge: Cambridge, 1.
} 
might have an entire proposition, this is not necessary. As with speech acts, intentional states have directions of fit and conditions of satisfaction.

The concepts of Network and Background determine the content of the conditions of satisfactions of an Intentional state. The first is the group of other intentional acts that serve as a context for the intentional act. The second is the set of practices and preintentional assumptions that are not intentional states or their conditions of satisfaction and that enable all representing to take place. It includes biological and cultural capacities, skills, stances, assumptions and presuppositions. ${ }^{18}$

In the context of third order cybernetics, the Network is the group of signs which can be interpreted to give meaning to the action which is being made, while the Background is not only a set of signs, but their understanding by an individual, its capacity to understand them, that is, his cognition, and his capacity to create them and that of others to understand them. There are points of convergence between both Network and Background, whereas the practices and assumptions that inform the Network might form part of the Background as well, however, the former is not a part of the latter.

Searle (2010) defines action as "a causal and Intentional transaction between mind and the world". Three are the elements of this transaction: prior intention, intention in action and bodily movement. This can be represented in the following way: ${ }^{19}$

action

$$
\text { prior intention }->\text { intention-in-action }->\text { movement }
$$

The prior intention is the initiation of the transaction by means of a representation of the whole action before it is undertaken, and because of this, the action is its condition of satisfaction. The prior intention is self referential, for it takes itself as the cause of action and it can be satisfied only if it's the cause of the action, that is, there has to be an element of volition. This has as a consequence that not all prior intentions are concreted into an action, some are never set in motion.

Intention-in-action, unlike prior intention which comes as a feature of premeditated or deliberate action, is not formed in advance of the action, but it provokes the act by representing its condition of satisfaction in that moment. Like prior intention, it is self

\footnotetext{
${ }^{18}$ Background. Dictionary of Philosophy of Mind. Retrieved from ,http://philosophy.uwaterloo.ca/MindDict/thebackground.html

${ }^{19}$ Prior Intention. Dictionary of Philosophy of Mind. Retrieved from http://philosophy.uwaterloo.ca/MindDict/priorintention.html
} 
referential, because only be deemed successful if it is the cause of the movement. ${ }^{20}$ Both the prior intention and the intention in action are the mental states that prologue the bodily movement and together they encompass an action.

Searle (1983) states that collective intentionality has the same elements of individual intentionality and the conditions of satisfaction of both are causally self referential. However, collective intention cannot be reduced to a grouping of individual ones or "I intend", but it is a "we-intend". He also states that to be able to put in action a set of individual intentions (as intention resides in the brain) each of the participants of collective intentionality has to presuppose that everyone is doing their part.

Although it might not always require speech acts, collective intentionality is used within an existing cognitive, cultural and linguistic frame, i.e. the Background, and it also has a set of assumptions and signs which provide the context for the actions, which is the Network.

Searle also makes a distinction between collective recognition and cooperation by saying that the former does not entail the presence of the latter. Recognition entails acknowledging the existence and function of something, while cooperation is a set of actions that are focused towards the attainment of a goal. The existence of an institution requires collective recognition, but actions within it do need cooperation.

\section{ii). Assignation of function and status functions}

To Searle (1983), language is a form of intentionality that has a biological basis. It is the basis for the ontological apparatus by which human beings create institutional facts. The primary function of language is to enable communication between its users and the content of said communication are intentional states, which communicate information about the world.

The assignment of functions is part of the apparatus necessary to account for the construction of social reality. ${ }^{21}$ Functions can be defined as "a cause that serves a purpose" (Searle 1983) and as he notes, they are observer relative and can be classified in: agentive, when the function assigned is related to human intentions, non-agentive, when this is not the case, and within the former, when the assigned function is that of intentionality. (Searle 1983).

Status functions require collective intentionality for their creation and continued existence and are functions that a person or entity has in virtue of a collective

\footnotetext{
${ }^{20}$ Intention in Action. Dictionary of Philosophy of Mind. Retrieved from http://philosophy.uwaterloo.ca/MindDict/intentioninaction.html

${ }^{21}$ Searle, J.R. (1995) The Construction of Social Reality. New York: Free Press, 13.
} 
recognition, they also require a language, as they need markers that indicate the existence of a function, although there are institutional facts, like money and wedding rings, that do not directly need language but they use semantics (Searle 1998).

Although language is a cognitive machine, the objects that are bestowed a function by means of a speech act are not. They are signs to be interpreted by the users of a language by means of their cognitive processes. The assignation of function by means of a language creates signs that are to be interpreted certain way by those with the same or similar Background and Networks.

\section{iii). Institutional facts}

Searle (2010) distinguishes between two types of rules: Regulative, which norm certain behavior, and constitutive, which create the possibility of the behavior they regulate. They first have the formula "Do X", while the second is "X counts as Y in context C".

Brute Facts are those that exist independently of human beings, while institutional facts depend of human institutions and are the result of an assignation of a function on a brute fact by means of collective intentional acts that use language as a vehicle. That is, when a brute fact is given a status function, they become an institutional fact, which means that they are intentionality and language dependent, that is, without the use of intentionality and language they would not be able to exist (Searle,1995)

The function of language is important in the assignment of function and the creation of institutional facts, as it is primarily a mean to convey information about the world (intentional states) among individuals. The double sense of fit of the declarative speech acts are the thing that makes possible for language to create institutional facts and also it does not have a prelinguistic equivalent. The formula of constitutive rules is applied to a brute fact or series of brute facts by means of a declarative speech acts (Searle, 2010).

As it was stated before, institutional facts are not cognitive machines, they are merely signs to be interpreted and recognized by members of a Society. To see an institutional fact is to interpret its meaning. They are the product of a continuous and circular communicative process, by means of which society organizes and reorganizes itself by means of speech acts, and their interpretation by means of cognition.

\section{iv). Deontic powers}

The declaration allows the creation of rights, obligations and duties by means of a commitment to the truth of what was stated, that is, the declarative speech act brings about deontic powers. In a "Status Function Declaration", there is a statement of how 
the world is and how it should be, and as this speech act is accepted by others, there is a change in the state of affairs of the world and social reality is created.

That is, to say "this is our leader", "that is his property" is to convey a meaning among a group of individuals and a function to a brute fact, to give an obligation to obey the commands of the leader and the right to demand him to behave within the scope of his legal attributions, to have an obligation of respecting the belongings of others and the right that one has of using, abusing and perceiving the fruits of an object. In being able to carry this meaning to others and to get them to consensus and to behave in a certain way is what holds human society together.

\section{b). Meso perspective: Social Systems}

\section{i). Social reality}

1though Searle does not explicitly give a definition or theory of Society, it happens that society is not only a collectivity of human beings, but it is also comprised by their knowledge and their institutional creation, that is, unlike Functionalist approaches which focus on structures or Action Theory that centers on individuals, this approach to Society accounts for both the individuals that comprise it and the institutional facts that they created and maintain through declarations and other speech acts. In summary, Society is more than the sum of its parts.

The micro level of analysis accounts the process of social ontology by means of which institutional facts are created. The meso level of analysis will deal with social systems, that is, individuals grouped towards the attainment of a goal which set a boundary to separate themselves from their environment. This term is an equivalent to that of organization.

Social systems as a meso approach overlaps with social ontology, because it is a form of social interaction by means of language and speech acts, but it is distinguished from it because for the purposes of having a discernible unit of analysis. The micro perspective was used to describe the actions to be analyzed.

Johannes van der Zouwen and Cor van Dijkum (2001) define social system as "a system in which actors, their actions and/or their communications form the elements... a set of 
interacting elements separated from its environment by a boundary". 22 Social systems can determine their boundaries in the following manner: ${ }^{23}$

- Focusing on the actors to determine who belongs or not to the organization.

- Centering on the social distance between actors within the organization and others, that is, the social relations of a specific type that involve certain actors.

- Focusing on the nature of the activities performed by the organization.

\section{ii). Defining features of social systems}

Social systems have the following features: ${ }^{24}$

- Openness of the system: They can receive input from their environment and send out put to the environment. Although during this transformation, delays may occur.

- Self structuring: They are able to set and reset the boundaries that distinguish it from the environment.

- Self maintaining: They are able to sustain themselves by means of taking resources from the outside.

- Self reflective: Social systems are able to make observations about their state, input and output. Not only are they self- observing, but they are reflexive, that is, they can reflect on themselves and generate expectation about future situations.

- Self creative: Because individuals that form a social system are self-conscious and have a capacity for creation, have the ability to create new systems and structures, and recreate existing ones.

- Teleological and teleonomical: Social systems are able to set their own goals, but at the same time they respond to the environment. They are learning systems.

- Homeostatic: Social systems are able to maintain themselves within a turbulent, unpredictable, and uncontrollable environment.

\footnotetext{
${ }^{22}$ van der Zouwen J., van Dijkum C. Chapter 13. In Geyer F., van der Zouwen, J. (Eds.) (2001) Sociocybernetics: Complexity, Autopoiesis and Observations of Social Systems. Westport, Connecticut:Greenwood Press 225, 226.

${ }^{23}$ Scott, W.R., Davis, G.F. (2007) Organizations and Organizing. Upper Saddle River, NJ: Pearson, Prentice Hall 152, 153.

${ }^{24}$ Scott, W.R., Davis, G.F. (2007) Organizations and Organizing. Upper Saddle River, NJ: Pearson, Prentice Hall 152, 153.van der Zouwen J., van Dijkum C. Chapter 13. In Geyer F., van der Zouwen, J. (Eds.) (2001) Sociocybernetics: Complexity, Autopoiesis and Observations of Social Systems. Westport, Connecticut:Greenwood Press 225, 226. Fuchs, C., Concepts of Social Self-Organization. Retrieved from http://www.self-organization.org/results/papers/pdf/hsicpaper4.pdf
} 
Language is a cognitive machine that is omnipoietic, that is, with its inputs it can create both things other than itself and also their own components. Self creation distinguishes social system from allopoietic and autopoietic systems. Social systems are able to create new structures and components or change existing forms to adapt to both an environment or a purpose. This differs from the idea of autopoiesis, which consists of systems being able to create their own components within a closed space.

Social systems are operationally open, while autopoietic systems are closed. Social systems are both teleonomical and teleological, but autopoietic systems which are only teleological. This means that social systems can have constant feedback with its environment and also determine the boundaries that mediate between them, they can ponder between outside pressures and the set goals and with all that in consideration create and recreate themselves. Autopoietic systems produce their own components and can couple structurally with its environment, which irritates it and sets its "purpose" by means of an adaptation process.

The reason why social systems are self creative, is because languages have generativity, that is, they have the capacity to have an infinite number of sentences. That is, language is a creative cognitive machine, which by means of providing a symbolic basis for rationality, also endows it with self creation.

\section{Macro perspective: Society as a complex adaptive system}

\section{a). Society as a complex system}

The macro perspective of this study that of complex adaptive systems, comprises the totality of social systems and ontological and communicative processes. Social systems are complex systems for a variety of reasons:

First, they have a degree of hierarchy, a feature of complex systems proposed by Simon $^{25}$, as they are composed of subsystems, which in turn are composed of other subsystems and so on. They are also on the edge of order and chaos, that is, they are neither in complete order or in a chaotic state, as it can be seen that some subsystems can have sensitive dependence to initial conditions.

Social systems are time dependent seeing that they calibrate their actions according to its passage, learning from past experiences and attempting to foresee other

\footnotetext{
${ }^{25}$ Simon,H. The architecture of complexity, Retrieved from http://ecoplexity.org/files/uploads/Simon.pdf
} 
circumstances, they are agent based in both an individual and collective level, and they are reactive to the environment, which relates to the fact that they are open systems.

Finally, complex social systems are rule following, which reflects onto all of its functions and the way they are carried on, for agents, to have successful interaction need a certain measure of stability, which can only be achieved with the creation of rules and their enforcement.

Major Robert K. Calhoun and Captain Brendan F. Hayward of the Australian Army take the notion of a social complex adaptive system to a concrete level and summarize it: ${ }^{26}$

Complex adaptive systems consist of agents which comprise all the component actors of the system or society. These agents may be individuals, groups or systems. They include governments, political parties, local leaderships, potential or actual insurgents and their supporters, security forces, businesses, religious groups, gangs, criminal elements, schools, universities, the media and non-government organisations. The agents interact with one another and their environment continuously in both deliberate and spontaneous ways. Some of the consequences of these interactions are linear and predictable; others are not...

\section{b) Definition of society}

Having made a development of society from a trans disciplinary perspective, it is necessary to advance a definition of it, which will be the foundation of the rest of the theoretical effort made on this book.

Society can be thus defined as a group humans(as coherent high cognition systems) interconnected and interacting by means of a language that bridges their domains of cognition; they can act collectively and create rules and institutions to sustain and monitor their interactions, the latter which can vary in hierarchical dimension, content and purpose, having as a consequence a series of realities of their making which converge into a system that possesses changing degrees of complexity in response to external factors, such as the environment and the passage of time and internal factors such as the attitudes, feelings and collective identity of their human element.

\footnotetext{
${ }^{26}$ Calhoun, R., Hayward,B.F. Stabilising Complex Adaptive Systems Using Complexity Theory In Operational Design For Stabilisation And Support Operations, Australian Army Journal ,VII, 3. Retrieved from http://www.army.gov.au/lwsc/docs/CalhounHayward_Stabilising_Complex_Adaptive_Systems.pdf
} 


\section{Conclusion}

FIRST.- Language is the key instrument for the creation of social systems and the generation of knowledge, but at the same time is part of the latter. Language is the cohesive agent in human interaction, though it Society comes to be.

SECOND.- Knowledge departs from the dichotomy of a knower and the things he knows, which are separate from him.

THIRD.- Language implies a dichotomy between the speaker and the things he speaks. Language is a creative cognitive machine.

FOURTH.- Society is more than the sum of individuals: Knowledge and the institutions created by means of speech acts are part of it as well. Society is more than a sum of people, it is also their knowledge and the institutional facts created by them. It is a combination of action and function.

FIFTH.- Communication is a circular process, so is the generation of knowledge and so are social interactions.

SIXTH.- There is a biological basis for Society, but the latter is not a living system.

SEVENTH.- Because they are at the same time observing and observed systems, social systems have features of first and second cybernetic systems.

EIGHT.- Institutional facts need to be recognized to be maintained, otherwise, the social structure they hold collapses, this is done by means of communication, which is circular, and language.

NINTH.- Social systems are self creative, because languages have generativity, that is, they have the capacity to have an infinite number of sentences. Social systems can take many shapes and configurations, language transcends through all of them.

TENTH.- Society is a complex system because it comprises the totality of interactions and social units.

\section{Sources}

\section{Electronic}

1. Calhoun, R., Hayward,B.F. Stabilising Complex Adaptive Systems Using Complexity Theory In Operational Design For Stabilisation And Support Operations, Australian Army Journal ,VII, 3. Retrieved from http://www.army.gov.au//wsc/docs/CalhounHayward_Stabilising_Complex_Ad aptive_Systems.pdf 
2. Dictionary of Philosophy of Mind, http://philosophy.uwaterloo.ca/MindDict/index.html

3. von Foerster, H., Cybernetics of Cybernetics. Retrieved from http://jlombardi.net/pdf/cyber_cyber.pdf

4. Fuchs, C. Concepts of Social Self-Organization. Retrieved from

5. http://www.self-organization.org/results/papers/pdf/hsicpaper4.pdf

6. Simon, H. The architecture of complexity, Retrieved from http://ecoplexity.org/files/uploads/Simon.pdf

7. Stanford Encyclopedia of Philosophy http://plato.stanford.edu/

8. Umpleby, S.A. What comes after second order cybernetics? Retrieved from http://www.gwu.edu/ umpleby/recent_papers/2001_what_comes_after_second order cybernetics.htm

9. Vanderveken, D. Meaning and Speech Acts, (Vol. I). Retrieved from http://www.uqtr.ca/ vandervk/elementary_illocutionary_acts.pdf

10. Web Dictionary of Cybernetics and Systems http://pespmc1.vub.ac.be/ASC/indexASC.html

\section{Bibliographical}

1. Geyer, F., van der Zouwen, J. (Eds.) (2001), Sociocybernetics: Complexity, Autopoiesis and Observations of Social Systems. Westport, Connecticut: Greenwood Press.

2. Johannssen, J., Hauan, A. (1994) Communication- A Systems Theoretical Point of View (Third Order Cybernetics), Systems Practice, 7(1).

3. Lesne, A., Bourgine, P. (Eds.) (2006) Introduction. In Morphogenesis. Origins of Patterns and Shapes. Dodrecht: Springer.

4. Maturana, H.R., Varela, F.J. (2012) Autopoiesis and Cognition: The Realization of the Living. Dodrecht: D. Reidel Publishing Company.

5. Ohio State University (2011) Language Files: Materials for an introduction to language and linguistics.(11th ed.) Columbus: Ohio State University.

6. Searle, J.R. (2010) Making the Social World. New York: Oxford University Press.

7. Searle, J.R. (1995) The Construction of Social Reality. New York: Free Press. 
Roberto Gustavo Mancilla

8. Searle, J.R. (1998). Mind, Language and Society. Basic Books.

9. Searle, J.R., (1983) Intentionality: An essay in the philosophy of the mind. Cambridge: Cambridge.

10. Scott, W.R., Davis, G.F. (2007) Organizations and Organizing. Upper Saddle River, NJ: Pearson, Prentice Hall. 